\title{
Impact of poisonous plants on the livestock industry
}

\author{
LYNN F. JAMES, DARWIN B. NIELSEN, AND KIP E. PANTER
}

\begin{abstract}
James is research leader and Panter is research animal scientist at USDA-ARS Poisonous Plant Research Laboratory, Logan, Utah 84321; Nielsen is agricultural economist, Utah State University, College Agriculture. Economics Department, Logan 84322.
\end{abstract}

\section{Abstract}

Livestock poisoning by plants is one of the serious causes of economic loss to the livestock industry. Losses can be classified as either direct or indirect. Direct losses include deaths, weight loss, abortions, lengthened calving intervals, decreased efficiency and other effects on the animals. Losses from death and some reproductive losses in the 17 western states are estimated at $\$ 340,000,000$. In addition to these are the indirect losses such as fencing, herding, supplemental feeding, medical costs, management alterations, and loss of forage which are associated with efforts to prevent or minimize poisoning of livestock by plants.

Nearly all plant communities include poisonous plants, thus, most grazing animals are exposed to intoxication. However, the presence of these plants does not cause poisoning. Poisoning is usually associated with management errors, lack of forage due to range conditions, drought, and other events that would cause livestock to consume vegetation normally unacceptable. Often a sequence of events, such as storm, frost, cold, and other occurrences can infuence an animal to where it will eat too much of a toxic plant too fast.

Key words: toxic, cattle, sheep

On every continent the area devoted to grazing livestock exceeds that of planted and cultivated crops. The livestock produced on this 1.5 billion hectares of grazing land (about $50 \%$ of the land surface) play a critical role in the food, fiber, energy, pharmaceuticals, and industrial sections of the global economy.

Livestock products in the United States accounted for about $55 \%$ of the total farm cash receipts in 1987 . Sales of cattle and calves were among the top 5 contributors to farm cash income in 44 states and were number one in 18 states. Additional income is generated in the handling, processing, and sale of animal products in other segments of the agricultural economy. This does not include cash receipts from sheep. These livestock obtain a substantial portion of the dietary needs from the rangelands and pastures (private and public) of the country.

It is not uncommon to find poisonous plants growing on both sown, natural, and private and public grazing lands. In fact, poisonous plants can be found growing in most plant communities. These plants, under certain conditions, can be hazardous to grazing livestock.

Livestock poisoning by plants has been a problem to livestock producers of the United States since the pioneers first grazed their cattle and sheep on the pastures and rangelands of this country. Poisonous plants are not only disruptive to the harvesting of the forage produced on the 400 million hectares rangeland and pastures of the United States, but are also one of the most important economic impediments to profitable livetock production.

Invited paper presented at the symposium "Ingestion of Poisonous Plants by Livestock" at the Society for Range Management Annual Meeting, Reno, Nevada.

Manuscript accepted 8 May 1991.

\section{Economic Losses}

The elusive, hard-to-define, almost impossible-to-count nature of the problem has made it very difficult to set an actual dollar value on the economic losses sustained because of livestock poisoning by plants. This problem has led many to describe the economies of the problem with vague statements such as "poisonous plants are a principal cause of economic loss to the livestock industry" or "poisonous plants exert a costly toll...". This vague approach is also due in part to the diversity of the problem: different plants involved, variety of toxic effects, variation in morbidity and mortality from year-to-year, and so on. Yet despite the fact that cost figures are hard to obtain and are somewhat tenuous, if we are to deal with the problem of livestock poisoning by plants, we must at least describe the impact that poisonous plants have on livestock production and develop a best estimate of economic losses. Management decisions are based on an understanding of costs and benefits associated with the decision-making process. In the case of poisonous plants, we must have some idea of cost if we are to say something about risk and evaluate improvements, range programs, land values and other factors in livestock production programs where poisonous plants are involved (James 1988, Nielsen and James 1991).

Economic losses due to livestock poisoning by plants can be divided into 2 parts: (1) direct losses and (2) indirect losses (James 1978).

\section{Direct Losses}

Direct losses of livestock involve the economic impact of poisonous plants on the animal. These losses include such things as death, emaciation, slow growth, decreased reproductive efficiency, abortion, birth defects, and other effects.

\section{Death Losses}

Deaths of livestock poisoned by plants, especially those dying acutely and in large numbers, have received more attention than other losses. This attention is probably due to the fact that these events are emotionally striking. These losses can be counted, a value attached to them, and the economic impact on a livestock operation calculated. These catastrophic events have been associated with halogeton and lupine poisoning in sheep, larkspur, and shinnery oak poisoning in cattle, cow losses in association with pine needle and broom snakeweed abortion, and many others. Much harder to identify are the death losses of only a few animals at a time which, in total, is probably more important economically than the large catastrophic losses. These losses are not as emotionally or economically distressing and are harder to identify because owners may not attempt to ascertain the cause of the death, because (1) small losses seem less important, (2) these losses may be considered a "normal" cost of livestock production, (3) livestock killed under range conditions may not be discovered, (4) length of time the animal has been dead, or (5) lack of adequate diagnostic 
procedures. Thus, in considering death losses, some can be accounted for but for many others only a best estimate is available.

\section{Performance Losses}

The National Academy of Science estimated that $8.7 \%$ of the nutritional ailments in foraging livestock were due to poisonous plants (Ensminger et al. 1955). Poisoning, such as sneezeweed or bitterweed poisoning in sheep or locoweed poisoning in all livestock, usually results in wasting of the animal. These animals may eventually die or become less productive. Animals poisoned on the pyrrolizidine-containing plants, such as senecio, crotalaria, and many others, may not die for long periods of time after consumption of the plant because of the chronic nature of the intoxication. In any of these cases, the animal may be removed from the cause, time passes, and therefore, the loss may not be associated with a poisonous plant. These unidentified losses can be significant, but the cost can be very difficult to determine.

Plants that cause wasting or poor performance have been mentioned. The degree of wasting varies. In some cases, the decrease in performance is obvious, in others it is hardly noticeable. Any time an animal grazes a poisonous plant and becomes sick, or its functional efficiency decreases, there will be a loss of performance. In most cases of photosensitization, animals do not die; but the recovery period is long and weight losses are high. Photosensitization is often associated with the hepatotoxic plants and, therefore, may have chronic effects due to liver damage.

Neurological damage due to locoweed consumption reduces value of livestock, especially horses, which are no longer useful for riding or draft purposes. Losses, due to a decrease in functional efficiency, are difficult to evaluate and at present we do not have enough information to make an economic statement as to the losses.

\section{Reproduction Losses}

Several plants can cause abortion in livestock. The principal abortifacient plants are locoweed in all livestock; ponderosa pine needles in cattle; and broom snakeweed in cattle, sheep, and goats (James et al. 1967, Stevenson et al. 1972, Kingsbury 1964). Other plants such as those high in nitrates have been associated with abortion in livestock. Serious encounters with these plants can result in abortions approaching $100 \%$, but $20-30 \%$ is more common.

Abortions from locoweed poisoning can occur anytime during gestation when the animal grazes locoweed for more than a short period of time. In addition, many lambs born to poisoned ewes are small and most do not survive. Mortality rates are high even if lambs born to ewes grazing locoweed appear normal.

Ponderosa pine needles can cause abortions in cows, particularly during the last trimester of gestation. Those calves that survive birth are usually weak, are more susceptible to disease, and mortality is high. Many cows have retained placentas, including some with full term pregnancies, and mortality rate is high. Pine needles, broom snakeweed, and other causes of abortions lengthen calving interval because retained placentas delay estrus and breeding by as many as $60-120$ days. The lost growth associated with 60 days reduction in growth time could exceed $\$ 100$ per calf. Over a 3-year period these losses could exceed those associated with the loss of one aborted calf. An abortion, whatever the cause, can reduce an operation's cash flow by about $\$ 500.00$ on the value of the calf at weaning and up to another $\$ 500.00$ for medical cost, possible cow replacement cost, losses in future productive performance and in some cases death of the cow. Poisoned cows produce less milk than normal and are less maternal. Some of these cows may become infertile. Estimates of the economic impact of pine needle abortion range from $\$ 6,000,000$ to $\$ 20,000,000$ (Nielsen and James 1991). Personal observations indicate that the higher figure
Cows grazing broom snakeweed, especially during the last trimester of pregnancy, may abort. Calves born near term are usually small and weak but may survive if given proper care. A high percentage of these cows have retained placentas and some cows die. Broom snakeweed is also toxic to some animals regardless of abortions. The economic impact of broom snakeweed, in western Texas and eastern New Mexico, has been estimated at approximately $\$ 40,000,000$ (Torell et al. 1988). This does not include all broom snakeweed losses within this area nor does it include other geographical areas.

Anything that causes a cow or ewe to lose weight, go off feed, not feel well (become sick) can interfere with that animal coming in estrus and, subsequently, delay the time of parturition. A number of plants such as locoweed, photosensitizing plants, nitratecontaining plants and many others, could be involved in this kind of scenario. For example, a cow could become ill from grazing larkspur at the time she should show estrus, or an outbreak of photosensitizing could cause a cow to become ill and delay estrus.

Fertility is the most important economic factor in livestock production. Locoweed interferes with semen quality, oogenesis, and libido; seleniferous plants interfere with estrus; certain plants, such as some clovers, are estrogenic, thus interfering with fertility. The effects of plant toxins on fertility in livestock can be an important problem, but are very difficult to quantify.

Cows or ewes that die, or become nonproductive, or for some other reason go out of a producer's herd, must be replaced if herd numbers are to be maintained. This replacement can be accomplished by (1) purchasing replacements and (2) raising replacements. There are problems associated with both methods of obtaining replacement females. Purchasing replacement females from outside the resident herd can introduce animals that are not adapted to the new environment, thus are more susceptible to poisoning by plants and other problems than are native animals. Time must be allowed while these animals adapt to their new environment. They may not adapt to available forage, i.e., from shrub range to a grass range. The raising of replacement heifers is expensive. Time is lost while a heifer matures to an age she can reproduce, some replacements must be culled, and heifers wean lighter calves, thus decreasing the overall functional efficiency of the herd and cash flow of the owner. Whatever the method of obtaining replacement females, if the cause was due to poisoning by plants, the cost must be part of the overall economic impact of poisonous plants on livestock production.

Until recently, birth defects have not been counted as an economic factor in livestock production. A cyclopian-type malformation has been associated with ewes grazing Veratrum californicum on the 14th day of gestation (Binns et al. 1963). Incidence was as high as $25 \%$ in certain years. An equal percentage of dry ewes was also apparently due to embryonic death (Van Kampen et al. 1969). Skeletal malformation in calves has been associated with the consumption of lupine by cows during the $40-70$ th days of gestation (Shupe et al. 1967). Locoweed, poison-hemlock, and other plants have been associated with birth defects in livestock (James et al. 1967, Keeler 1978). These deformed animals are an economic loss because they don't survive or are uneconomical to keep.

\section{Indirect Losses}

Indirect losses include those activities or costs that are incurred by a livestock operation to prevent losses or costs incident to livestock poisonings by plants. Indirect losses (cost) include fences built and maintained to manage livestock at risk due to poisonous plants; herding livestock to prevent poisoning; supplemental feeding to prevent poisoning; altered grazing programs which may result in increased costs or grazing inefficiency; medical costs incident to poisoning; and forage lost because it could not be 
harvested at the proper time or intensity. These costs are difficult to quantify, yet are present.

Other losses exist, some of which do not fit into the usual economic analysis, but, nevertheless, have effects on a livestock operation. Included in this group are adverse effects of stress on management, risk and attendant problems, effect on land values and grazing permits.

What then are the total economic effects of livestock poisoning by plants? If it can be estimated, how valid is the estimate?

Nielsen and James (1991) used 1989 prices and numbers and estimated the economic loss of livestock in the seventeen western states at $\$ 340,000,000$ based on a $1 \%$ death loss in cattle, a $3.5 \%$ death loss in sheep, and a $1 \%$ decrease in calf and lamb crops due to poisonous plants. This cost will vary with inventories and prices (Nielsen and James 1991). Others have used a mortality rate between 2 and 5\%, which suggests that the estimate Nielsen and James (1991) used is reasonably accurate. The $1 \%$ loss in reproduction seems moderately reasonable in light of the many effects of poisonous plants on reproduction and the size and scope of these problems. Producers in the other 31 contiguous states also experience losses due to poisonous plants (Miller et al. undated). This estimate did not include other direct losses such as decreased growth, decreased performance, and effects on reproduction other than other abortions and birth defects, nor does it include indirect losses. Thus, the above estimate underestimates the economic impact of poisonous plants on livestock production in the United States.

Reagor (1981) suggested that, in Texas, poisonous plants "cause more dollar losses than any disease." If this is true for Texas it would quite likely be true for Arizona and New Mexico. Parker suggested the same was true for Utah. Marsh (1929) estimated the average animal death loss at $3-5 \%$ with losses in states such as Wyoming being as high as $14.6 \%$. Durrell et al. (1952) estimated losses as high as $8 \%$ in Colorado. In New Mexico (Anonymous 1957) it has been estimated that the losses of livestock due to poisonous plants were from less than $1 \%$ to as high as $20 \%$ with an average over time of $2 \%$. The USDA, 1968, estimated annual countable losses in the western United States at 3-5\%. Gay and Dwyer (1967) suggest that over the entire western ranges, the average death loss is 2 to $3 \%$, and further in dollars and cents, the losses in reproduction and weight gains of animals that are poisoned, but do not die, probably exceed the death loss. These figures suggest that our estimates are valid at least in the western United States. If anything, current estimates are on the modest side.

Another method that can be used to estimate the economic losses due to poisonous plants is to take figures and/or statements from various states or other sources; use those figures to project into other states of similar character, and ultimately come up with a figure that can be used as a total estimate. For example, it was estimated that the economic losses from poisonous plants in Texas in the late 1960s was about $\$ 100,000,000$ (Sperry et al. undated). Estimates based on 1990 livestock prices would be somewhat higher. Based on 1986 livestock prices, it was estimated that losses due to broom snakeweed in eastern New Mexico and western Texas were $\$ 40,000,000$ (Torell et al. 1988). This figure includes most but not all losses due to broom snakeweed. Reagor (1981) reported that oak brush caused greater economic losses than any other poisonous plant in Texas. Bitterweed is the poisonous plant most important to the sheep industry in Texas. Senecio has been identified as one of the most serious problems to cattle in Texas. Locoweed in certain years can spell disaster to a livestock operation. Therefore, the $\$ 100,000,000$ probably underestimates losses due to poisonous plants in Texas (Sperry et al. undated). Death losses in California, due to poisonous plants, may total $\$ 27,500,000$
(Di Tomaso undated). This estimate does not include all losses. Thus, these sources suggest that $37 \%$ of the losses estimated by Nielsen and James for 1989 in the 17 western states, occur in 2 states. States such as New Mexico, Arizona, Utah, Colorado, and Montana have problems similar to those in Texas. This would suggest that the estimate of Nielsen and James is low, but surely can be used with confidence that losses are not overestimated.

Another method that can be used to estimate economic loss, which requires acquaintance with poisonous plant problems of the country, is to look at individual losses in certain areas and project to other areas for the same plant. By evaluating the losses due to some of the principal known poisonous plants one can come up with a fair estimate. Interestingly, the value obtained from this approach agrees well with the more rigorous estimates.

In attempting to develop estimates of economic loss due to poisonous plants, one is led to the conclusion that indeed poisonous plants are one of the most important causes of economic loss to the livestock industry.

\section{Poisonous Plants as Forages}

Poisonous plants are not considered as forages for livestock, yet there are times when livestock can graze these plants without apparent harm. A plant can be defined as poisonous only in terms of its toxic effect on the animal that consumes it. A plant does not poison an animal unless it is eaten. The poison is in the dose, i.e., how much plant was eaten and how fast it was eaten. When is a poisonous plant a forage and when is it a poisonous plant (Bowns 1988, Taylor and Ralphs 1988)? Some plants are toxic to an animal in such a way that they should never be grazed. This group includes plants such as pyrrolizidine alkaloid-containing plants, locoweeds and sneezeweeds. Plants such as certain lupines, halogeton, and larkspur under certain conditions can be grazed extensively with no apparent harm to the animal. Perhaps some forage value should be given to this group of plants. If this were done then the conditions under which these plants could be safely grazed would need to be specified.

\section{Toxin Level in Plants}

The toxicity of most poisonous plants varies with stage of growth, temperatures, site, precipitation, light, soils, and weather conditions. Immature larkspur is more toxic than mature. Cyanogenetic plants such as chokecherry are more toxic after a frost. Cyanide content in plants varies on a diurnal basis, and plants are more toxic during a light rain; nitrate can be higher in plants during a drought. Broom snakeweed is more toxic when grown on sandy soil than on limestone soil (Kingsbury 1964). Phalaris staggers developing from tryptamine alkaloids in reed canary grass is more likely to develop during cloudy and foggy weather (Hartley 1978). Plants accumulate more selenium when soil in which they grow comes from certain parent materials.

Certain animal factors also determine a plant's toxicity. Sheep are more resistant to larkspur than are cattle (Olsen 1978). Rumen microflora can detoxify certain plant toxins such as oxalate (James et al. 1967). An animal that is full is more resistant to intoxication than a hungry one, i.e., the toxin may be diluted in the full animal and the animal will not eat as much as fast. The liver can detoxify cyanide very rapidly, but metabolizes pyrrolizidine alkaloids to the more toxic pyrroles.

\section{Conditions of Poisoning}

What, then, are the conditions under which a plant containing a toxin/s becomes a plant poisonous to livestock (Everist 1981)? Poisoning of livestock by plants is usually the result of management errors, range conditions, or kinds of animals rather than the 
presence of poisonous plants. However, there are some exceptions to this generalization.

We are long past the time we can pass off poisonous plants as a symptom of an overgrazed range (Dwyer 1978). Forage availability can be influenced by drought or overgrazing (i.e., either a temporary short-term effect or a longer-term grazing effect of a more permanent nature); or storms which may cover forage with snow; or cause animals to move into trees or other areas for protection; or a local problem where animals have been or are being trailed; or any activity that decreases forage availability. Improperly placed fences may create problems of a forage shortage, especially during times of the year when animals expect to be moved and may accumulate in areas that place them at risk because of poisonous plants. In some cases, grazing early in the spring or late in the fall when some poisonous plants are the only green forage available may lead to poisoning. Livestock losses due to poisonous plants have been associated with trucking, driving, or penning of animals. During these times animals may become hungry due to being deprived of feed or water or changes in the environment or weather (frost, precipitation, wind, etc). Increased stress from handling, hunger, and other such conditions can lead to animals grazing a poisonous plant.

\section{Management Strategies to Mitigate Effects of Poisonous Plants}

Poisonous plants can affect management in a number of ways. Among these can be included time allocations, grazing strategies for livestock operation, livestock programs, forage utilization and land values, and the overall ability of the operator to conduct business in a normal way.

The effects on time include those activities imposed on managers to avoid problems caused by the presence of poisonous plants. Moving and checking cattle and sheep and building fences all take time that could be directed to other activities. This is an example of an opportunity cost associated with poisonous plants.

Changes in grazing strategies may avoid problems or, in some instances, create problems. The changes may require adjustment in other activities.

Calving or lambing time may need to be changed so livestock do not graze poisonous plants during times when the unborn calves or lambs are likely to be affected, as in the case of the lupine-induced crooked calf condition or plant-induced abortions. Cattle grazing ranges or pastures containing poisonous plants should be checked more often than when no poisonous plants are present. Pastures must be checked frequently to monitor the extent to which plants are grazed. Trailing, trucking, corralling, or placing nonconditioned livestock on unfamiliar ranges must be done with care to avoid problems of plant poisoning. The presence of plants that can be poisonous to livestock on a range does not mean that poisoning is imminent. But it does mean that there must be a continuous awareness and management adjusted to avoid problems. It is possible that losses can occur, oftentimes large ones. Thus, the risk factor of ranching is increased.

The building of fences and other such activities are not only costly, but also time-consuming to maintain. In the construction of fences, as with any other management decision, poisonous plants should be taken into account.

Many livestock losses from poisonous plants are associated with management or lack thereof. We can manage livestock and/or grazing lands in such ways as to enhance the probability of poisoning.

Most livestock are poisoned by plants under open range or pasture grazing situations. Thus, most livestock poisoning of necessity will be prevented in the same arena. Information needed to develop management strategies for prevention will come from essentially four areas of study: 1

1. Veterinary medicine

2. Chemistry

3. Animal science

4. Range and plant science

Scientists in veterinary medicine provide information on descriptive clinical and morphological pathology (diagnosis), mechanism of action of the toxin, toxicology (i.e., time/dose response information), and possible treatment, physiological, and pharmacological changes caused by the toxin.

Chemists provide isolation and characterization of the plant toxins, qualitative and quantitative measurement of the toxins, mechanism of action, structural specificity of the toxin, concentration of plant toxins as affected by environment, stage of growth, and stress (drought, grazing, cold).

Animal scientists provide information on metabolism of toxins by rumen flora, effects of toxins on reproductive physiology, animal response of these plants in the diet, and toxicology.

Range and plant scientists can provide information on conditions under which poisoning occurs, i.e., acceptability of the plant to the grazing animal, what happens when a plant changes from a forage to a toxic plant, animal/plant interaction, dynamics of plant toxins as affected by environment and stage of growth.

The above discussion does not imply that the description of each area of study is confined to those activities listed. There is planned overlap between the various disciplines of investigation.

The following are some examples of management programs that have been developed to prevent or minimize livestock losses from poisonous plants.

\section{Veratrum}

Bred ewes grazing certain mountain range areas in Idaho had lambs with cyclopian facial and skeletal birth defects. The incidence of these birth defects varied from about 5-25\% of lambs born. The incidence of dry ewes in the band was higher by about the same percentages as birth defects. The livestock people involved perceived this as a genetic problem. It was shown that ewes grazing Veratrum californicum on the 14th day of gestation gave birth to lambs with birth defects as those described (Binns et al. 1963). The dry ewes were due to embryonic or fetal deaths resulting from consumption of the Veratrum. The toxin was isolated and characterized (Keeler and Binns 1964, 1966a,b). (The identification of the toxin resulted in this information being used as a model to study facial birth defects in humans). Ranchers grazing sheep on these ranges generally saved the areas where the Veratrum grew to flush the ewes prior to breeding. The problem was overcome by grazing ewes and lambs on these areas and breeding on areas where little Veratrum grew. The information needed was the causative agent (Veratrum) and the time of insult (14th day) to the developing embryo and the solution was obvious.

\section{Lupine}

Cows grazing certain range areas in California, Oregon, Washington, Idaho, and Utah gave birth to calves with skeletal birth defects and cleft palates. Research demonstrated that cows grazing certain species of lupine during days 40-70 of gestation might give birth to calves so deformed (Shupe et al. 1967). The toxin was identified as the alkaloid anagyrine (Keeler 1976). It was shown that the level of this toxin in the plant was high during the vegetative stage and decreased as flower stage approached and was again high in the seeds (Keeler et al. 1976). By adjusting the time of breeding the cows and the time of grazing the lupines, the problem was minimized. Information needed was the plant responsible, the toxin and how it varied in the plant over time, and the time of insult

\footnotetext{
James, L.F. Staffing plan USDA/ARS Poisonous Plant Research Laboratory, Logan, Utah 84321
} 


\section{to the fetus.}

\section{Conium}

The same type of skeletal malformation observed in association with lupine was observed in cattle grazing Conium maculatum (Keeler 1974, Keeler and Balls 1978). The toxin, coiine, decreased as the plant matured. With this information, the condition can be prevented.

\section{HMD-Locoweed}

The incidence of congestive heart failure, High Mountain Disease (HMD) or brisket disease in cattle, primarily calves, can approach $100 \%$ on high elevation ranges that have locoweed growing on them. It was shown that locoweed consumption by cattle grazing these ranges was the cause of the high incidence of HMD (James et al. 1986). It was shown that it took $\mathbf{4 0 - 4 5}$ days grazing locoweed for the HMD to develop. On 1 range studied, 300 cattle were grazed about 75 days under a 4 pasture rest rotating grazing system. The system was changed to graze 3 pastures simultaneously, rest 1 and increase cattle numbers, so the range was grazed about 40 days (Ralphs et al. 1984). The incidence of HMD decreased to near zero. Information needed to alter grazing programs was the association of locoweed consumption with the high incidence of HMD and the etiology of the locoweed/HMD condition.

\section{Halogeton}

Halogeton (oxalate) poisoning has been a serious problem to the sheep industry in the Great Basin. However, sheep can graze large amounts of halogeton under normal grazing conditions (Bowns 1988). Research has shown that sheep can be maintained, at least for short periods of time, on a diet of halogeton. It takes 24 hours for them to consume this amount of plant. ${ }^{2}$ This amount of plant can be lethal to about 5 sheep if they consume the halogeton in about 30 minutes. It has been shown that preconditioning a sheep for 4-5 days on light stands of halogeton or shadscale, increases the sheep's tolerance to oxalate about $21 / 2$ times because of the ability of the rumen microflora to degrade it to nontoxic compounds (James et al. 1967). It has also been shown that halogeton is high in total salts. It requires about $5 \mathrm{gal}$ of water to excrete $1 \mathrm{lb}$. of salt (Pister et al. 1950). Thus, sheep grazing halogeton will require a higher water intake (James and Cronin 1974). If water intake goes down, feed intake will decrease, the animal becomes hungry, and when water is provided, the animal will consume available feed immediately and rapidly. Halogeton, in many of the arid and semiarid desert areas, abounds around watering areas. Withholding water or feed can cause animals to graze rapidly and less selectivity when these are supplied. Halogeton poisoning occurs when sheep eat too much halogeton too fast. Prevention lies in providing adequate water and forage, and allowing a conditioning period before animals are introduced to heavy stands of halogeton (James and Cronin 1974). All losses of sheep or cattle investigated by the author have resulted from allowing the animals to become overly hungry and then being given access to halogeton.

The following cases of grazing programs recommended to ranchers are results of information gained in the laboratory.

\section{Selenium}

A rancher observed that his cows failed to show estrus during the spring, summer, and into the early fall. These cows had been grazed on a range he had not previously used. Yearlings were kept on another range located some distance from where the cows grazed on the ranch. A survey of the range where the cows had grazed was conducted, and selenium indicator plants were observed over most of the area. A chemical analysis of the plant confirmed there was a

\footnotetext{
2James, L.F., unpublished data.
}

potential selenium problem. One of the principal effects of selenium on livestock is interference with reproduction (Olson 1978). The rancher was advised to change ranges with his yearlings and breeding cows. This was done and the problem was solved. The yearling cattle did well on the range having selenium accumulator plants.

\section{A. emoryanus}

About 500 or 1,500 cows were reported as visibly ill and many others were probably affected. The signs of poisoning were respiratory distress, goose stepping, cocked ankles (hind legs), and irregular gait. The cattle were distributed on 3 different ranches and on each ranch the cattle were in several pastures. Several suggestions were made, such as feeding or moving the cattle, none of which were viable solutions. Because of the signs of poisoning, it was suspected that the sickness was due to the consumption of Astragalus emoryamus, red stemmed pea vine (James et al. 1980). Samples were collected for identification and analysis. The plant was identified as A. emoryanus whose toxin is 3-nitro-1-propanol or iserotoxin (Stermitz et al. 1969). Miserotoxin level in the plant declines rapidly as the plant matures.

Each rancher was advised to place all his cattle on 1 pasture and leave them there until the forage was all consumed, then move them to another pasture, and so continue until the pea vine had matured. This grazing strategy accomplished 2 things. First a short period of intoxication as the cattle went into a new pasture and grazed the pea vine out and a period of detoxification after the plant was not available. The cattle were then moved to another pasture and the cycle repeated. Secondly the amount of plant available to any 1 cow was decreased as the numbers were increased in a given area. There was essentially no death loss in these cattle and those visibly ill recovered.

\section{Sneezeweed}

The poisoning of sheep by sneezeweed can be managed in the same way.

\section{Risks}

Livestock ranching is a risky business. It may not rain, prices may fall, cold wet weather may occur at calving or lambing, and many other risks are part of the business. There are risks in grazing ranges and pastures having poisonous plants. In some cases, the potential losses from a catastrophic poisonous plant problem could be of such a magnitude as to put the rancher out of business and force him to sell the ranch. Most ranchers will go to extreme positions to avoid risk situations that have any chance of putting them out of the ranching business. This is one reason poisonous plants can cause excessive stress on the owner-manager of the ranch. Whatever the risks, they must be evaluated in the setting of a livestock operation, and management decisions must be made that minimize the risks to which the operation might fall prey.

\section{Land Values}

When purchasing, renting, or in any other way evaluating a piece of property to be used for livestock grazing, one should inspect for poisonous plants. The costs that might be imposed by poisonous plants on ranges or pastures to be grazed by livestock should be considered in making the decision to buy or rent grazing land (Davis and James 1972, Godfrey et al. 1984).

If a particular ranch or ranching area gets a reputation of having serious poisonous plant problems, potential buyers will avoid the area or reduce the amount they are willing to pay for the ranch. Thus, it is possible for ranchers to lose value on their capital assets (real estate) because of this problem.

\section{Literature Cited}

Anonymous. 1957. Principal livestock poisoning plants of New Mexico ranges. Agriculture Extension Circ. 274. page 1. 
Binns, W., L.F. James, J.L. Shupe, and G. Everett. 1963. A congenital cyclopian-type malformation in lambs induced by maternal ingestion of a range plant, Veratrum californicum. Amer. J. Vet. Res. 24:1164-1175.

Bowns, J.E. 1988. The importance of poisonous plants as forage in the intermountain region. L.F. James, M.H. Ralphs, and D.B. Nielsen (eds.) p. 377-390. In: The ecology and economic impact of poisonous plants on livestock production, Westview Press, Boulder, Colo.

Davis, L.H., and L.F. James. 1972. Impact of poisonous plants on rangeland appraisal and management. Amer. Soc. Farm Managers and Rural Appraisers. 36:49-54.

Durrell, L.W., R. Jensen, and B. Klinger. 1952. Poisonous and injurious plants in Colorado. Colo. Exp. Sta. Bull. 412A. p. 1.

Dwyer, D.B. 1978. Impact of poisonous plants on Western grazing systems and livestock operations. p. 7-12. R.F. Keeler, K.R. Van Kampen, and L.F. James (eds), In: Effects of poisonous plants on livestock.

Ensminger, M.E., M.W. Galgan, and W.L. Slocum. 1955. Problem and practices of American cattlemen. Wash. Agr. Exp. Sta. Bull. 562. 1955.

Everist, Selwyn L. 1981. Poisonous plants of Australia. Angus and Robertson. Sydney, Australia.

Gay, C.W., and Dwyer, D.D. 1967. Poisonous range plants. Coop. Ext. Serv. Circ. 391, New Mexico State Univ., p. 1.

Godfrey, E.B., Nielsen, D.B., and N.R. Rimbey. 1984. The economic impact of poisonous plants on land values and grazing privileges. L.F. James, M.H. Ralphs, D.B. Nielsen (eds). In: The ecology and economic impact of poisonous plants on livestock. Westview Press, Boulder, Colo.

Hartley, W.J. 1978. Chronic phalaris poisoning or phalaris staggers. R.F Keeler, K.R. Van Kampen, and L.F. James (eds). p. 391-393. In: Effects of poisonous plants on livestock. Academic Press, N.Y.

James, L.F., J.C. Street, and J.E. Butcher. 1967. In vitro degradation of oxalate and of cellulose by rumen ingestion from sheep fed Halogeton glomeratus. J. Anim. Sci. 26:1438-1444.

James, J.F., J.L. Shupe, W. Binns, and R.F. Keeler. 1967. Abortive and teratogenic effects of locoweed plants on sheep and cattle. Amer. J. Vet. Res. 28:1379-1388.

James, L.F., and Cronin, E.H. 1974. Management practices to minimize death losses of sheep grazing halogeton infested ranges. J. Range Manage. 27:424-426.

James, L.F. 1978. Overview of poisonous plant problems in the United States. p. 3-5. In: Richard F. Keeler, Kent R. Van Kampen, and Lynn F. James (ed.) Effects of poisonous plants on livestock.

James, L.F., Hartley, W.J., M.C. Williams, and K.R. Van Kampen. 1980. Field and experimental studies in cattle and sheep poisoned on nitrobearing Astragalus plants on their toxins. Amer. J. Vet. Res. 41:377-382.

James, L.F., W.J. Hartley, D. Nielson, S. Allen, and K.E. Panter. 1986. Locoweeds (Oxytropis serecia) poisoning and congestive heart failure in cattle. J. Amer. Vet. Med. Assoc. 189:1549-1555.

James, L.F. 1988. Introduction. p. 1-4. Lynn F. James, Michael H. Ralphs, and Darwin B. Nielsen (eds.) In: The ecology and economic impact of poisonous plants on livestock production. Westview Press, Boulder, Colo.

Keeler, R.F., and Binns, W. 1964. Chemical compounds of Veratrum californicum related to congenital ovine cyclopian malformations: Extraction of active material. Proc. Soc. Exp. Biol. Med. 116:123-127.

Keeler, R.F., and Binns, W. 1966a. Teratogenic compounds of Veratrum californicum (Durand). I. Preparation and characterization of fractions and alkaloids for biologic testing. Can. J. Biochem. 44:819-828.

Keeler, R.F., and Binns, W. 1966b. Teratogenic compounds of Veratrum californicum (Durand) II. Production of ovine fetal cyclopia by fractions and alkaloid preparation. Can. J. Biochem. 44:829-838.
Keeler, R.F. 1974. Coniine, a teratogenic principle from Conium maculatum producing congenital malformations in calves. Clinical Tox. 7:195-206

Keeler, R.F. 1976. Lupine alkaloid from teratogenic and non teratogenic lupins. III. Identification of anagyrine as the probable teratogen by feeding trials. J. Tox. Environ. Health 1:887-898.

Keeler, R.F., E.H. Cronin, and J.L. Shupe. 1976. Lupine alkaloid from teratogenic and non teratogenic lupins. IV. Concentration of total alkaloid, individual major alkaloids and the teratogen anagyrine as a function of plant part and stage and their relationship to crooked calf diease. J. Tox. Environ. Health. 1:899-908.

Keeler, R.F., and L.D. Balls. 1978. Teratogenic effects in cattle of Conium maculatum and conium alkaloids and analogs. Clin. Tox. 12:49-64.

Keeler, R.F. 1978. Reducing incidences of plant-caused congenital deformities in livestock by grazing management. J. Range Manage. 31:355-360.

Kingsbury, J. 1964. Poisonous plants of the United States and Canada. Prentice-Hall, Englewood Cliffs. N.J.

Marsh, C.D. 1929. Stock-poisonous plants of the ranges. USDA Bull. 1245. p. 1 .

Miller, J.F., A.H. Kato, D.E. Davis, and J.McCormack. Undated. Georgia Cooperative Extension Service. Athens.

Nielsen, Darwin B., and Lynn F. James. 1991. Poisonous plants-Proc. 3rd Int. Symp., Iowa State Univ. Press, Ames.

Olsen, J.D. 1978. Tall larkspur poisoning in cattle and sheep. J. Amer. Vet. Med. Assoc. 173:762-765.

Olson, O.E. 1978. Selenium in plants as a cause of livestock poisoning. $p$ 121-133. R.F. Keeler, K.R. Van Kampen, and L.F. James (eds.) In: Effects of poisonous plants on livestock. Academic Press, N.Y.

Pister, W.J., J.C. Nesbitt, and B. Cardon. 1950. The influence of higher salt intake on the physiology of ruminants. Proc. Book Amer. Vet. Med. Assoc. 87th Annual Meeting. p. 154-159.

Ralphs, M.H., L.F. James, D.B. Nielsen, and K.E. Panter. 1984. Management practice reduce cattle losses to locoweed on high mountain ranges. Rangelands 4:175-177.

Reagor, John C. 1981. Overview of poisonous plant situations in the Trans-Pecos. p. la-le. In: Proc. Trans-Pecos Poison Plant Symp. Texas Agr. Ext. Serv., Fort Stockton.

Shupe, J.L., W. Binns, L.F. James, and R.F. Keeler. 1967. Lupine, a cause of crooked calf disease. J. Amer. Vet. Med. Assoc. 151:198-203.

Sperry, O.E., J.W. Dollahite, G.O. Hoffman, and B.J. Camp. Undated. Texas plants poisonous to I ivestock. Texas Agr. Exp. Sta. Bull. B. 1028.

Stermitz, F.R., F.A. Norris, and M.C. Williams. 1969. Miserotoxin a new naturally occurring nitro compound. J. Amer. Chem. Soc. 91:4599-4600.

Stevenson, A.H., L.F. James, and J.W. Call. 1972. Pine needle (Pinus ponderosa) induced abortion in range cattle. Cornell Vet. 62:519.

Taylor, C.A., Jr., and M.H. Ralphs. 1988. The importance of poisonous plants as forages in the prairies and Southwest. Lynn F. James, Michael H. Ralphs, and Darwin B. Nielsen (eds.) In: The ecology and economic impact of poisonous plants on livestock production. Westview Press, Boulder, Colo.

Torell, A.L., H.W. Gordon, K.C. McDaniel, and A. McGinty. 1988. Economic impact of perennial snakeweed infestations. Lynn F. James, Michael H. Ralphs, and Darwin B. Nielsen (eds.) In: The ecology and economic impact of poisonous plants on livestock production. Westview Press, Boulder, Colo.

USDA. 1968. 22 plants poisonous to livestock in the western states. USDA Agr. Info. Bull. 327.

Van Kampen, K.R., W. Binns, L.F. James, and L. Balls. 1969. Early embryonic death in ewes fed Veratrum californicum. Amer. J. Vet. Res. 30:517-519. 